Comunicação

[Communication]

\title{
Atividade antibacteriana de nanopartículas de polipirrol diante de Staphylococcus aureus isolados de amostras de leite de vacas e cabras com mastite
}

\author{
[Antibacterial behavior of polypyrrole nanoparticles against Staphylococcus \\ aureus isolated from cows and goats with mastitis]
}

\author{
A.C. Acosta ${ }^{1}$, A.S. Santos ${ }^{1}$, F.A.G. Silva ${ }^{2}$, E.S. Medeiros ${ }^{1}$, \\ H.P. de Oliveira ${ }^{2}$, M.M. Costa ${ }^{3}$, A.W.C Fernandes ${ }^{3}$, \\ J.W. Pinheiro Júnior ${ }^{1}$, R.A. Mota ${ }^{1}$
}

\author{
${ }^{1}$ Universidade Federal Rural de Pernambuco - Recife, PE \\ ${ }^{2}$ Universidade Federal do Vale do São Francisco - Instituto de Pesquisa em Ciência dos Materiais - Juazeiro, BA \\ ${ }^{3}$ Universidade Federal do Vale do São Francisco - Petrolina, PE
}

Os avanços na genética animal, no manejo, na alimentação e no desenvolvimento de novos desinfetantes e antimicrobianos permitiram um crescimento constante da indústria leiteira, não somente com o incremento da produção do leite, mas também com uma melhora significativa da qualidade higiênico-sanitária desse alimento. Porém, as infecções intramamárias (IMI) em ruminantes são as principais causas de perdas na indústria leiteira no mundo (Halasa et al., 2007). $S$. aureus apresenta vários fatores de virulência; um deles é a capacidade de formar biofilmes, importante mecanismo de sobrevivência das bactérias no nicho extracelular, que confere proteção diante do sistema imune do hospedeiro e ação de agentes antimicrobianos (Melchior et al., 2006).

O polipirrol (PPy) é um dos polímeros mais estudados como agente bactericida. A polimerização do pirrol produz cargas positivas ao longo da cadeia de PPy, sendo uma carga positiva formada a partir da união de três a cinco monômeros. As cargas positivas são responsáveis pela atividade bactericida, e esse efeito se deve à ruptura da membrana lipídica que recobre a bactéria, com a consequente lise celular por essas cadeias de polímeros (Varesano et al., 2013).

Observa-se um contínuo aumento no número de isolados de $S$. aureus resistentes à meticilina causadores de infecções em animais domésticos. Nesse sentido, novas estratégias são necessárias para identificar e desenvolver a próxima geração de medicamentos ou agentes antimicrobianos. Objetivou-se neste estudo avaliar a atividade antibacteriana de nanopartículas de polipirrol (PPy-NPs) em água diante de $S$. aureus produtores ou não de biofilmes, isolados de leite de vacas e cabras com mastites.

O estudo foi aprovado pelo Comité de Ética no Uso de Animais da Universidade Federal Rural de Pernambuco (UFRPE), com licença número 079/2014. Foram coletadas 1000 amostras de leite de vacas e 1253 de cabras, seguindo-se as recomendações do Conselho Nacional de Mastites (Laboratory, 1999). As amostras foram transportadas ao laboratório em caixas isotérmicas $\left(4^{\circ} \mathrm{C}-10^{\circ} \mathrm{C}\right)$, onde a lactocultura primária foi realizada em placas de ágar sangue a $5 \%$, e incubadas a $37^{\circ} \mathrm{C}$, realizando leituras às $24 \mathrm{~h}, 48 \mathrm{~h}$ e $72 \mathrm{~h}$.

$\mathrm{Na}$ identificação presuntiva do $S$. aureus, usou-se a metodologia descrita por Zecconi et al. (2006), e o diagnóstico confirmatório foi realizado mediante a reação em cadeia da polimerase (PCR), com a amplificação de um fragmento de 296 nucleotídeos do gene nuc. A extração do DNA foi realizada a partir das culturas bacterianas utilizando-se o kit comercial Wizard ${ }^{\circledR}$ Genomic

Recebido em 16 de novembro de 2017

Aceito em 10 de dezembro de 2019

E-mail: acabad80@gmail.com 
DNA Purification (Promega), seguindo as recomendações do fabricante. Os componentes da reação de PCR e as condições de amplificação foram descritos por Acosta et al. (2018).

A caracterização fenotípica para formação de biofilme foi realizada por meio do teste de aderência em microplacas de 96 poços, mediante a utilização da metodologia descrita por Merino et al. (2009), sendo usados como controles positivos e negativos S. aureus ATCC 29213 e $S$. epidermidis ATCC 12228, respectivamente. Realizaram-se leituras de densidade ópticas (DO) a 620nm no leitor de microplacas de ELISA (Multiskan Go Thermo Scientific). As amostras foram classificadas em quatro categorias (Stepanović et al., 2000), relacionando as médias de DO com a DO do controle negativo ( $S$. epidermidis ATCC 12228), sendo utilizados os seguintes critérios: sem produção de biofilme (DO amostra $\leq$ DO controle negativo), fraca produção de biofilme (DO controle negativo < DO amostra $\leq 2 \times$ DO controle negativo), moderada produção de biofilme $(2 \times \mathrm{DO}$ controle negativo $<$ DO amostra $\leq 4 \times \mathrm{DO}$ controle negativo) e forte produção de biofilme (DO amostra $>4 \times$ DO controle negativo).

Para a preparação de PPy-NPs, foi pesado 1,08g de dodecil sulfato de sódio (SDS) e solubilizado em água mili-Q (100mL), sendo, em seguida, adicionado a $500 \mu \mathrm{L}$ de pirrol $(0,483 \mathrm{~g})$. A suspensão resultante foi mantida sob agitação intensa durante 45min, e, logo após, uma suspensão aquosa $(50 \mathrm{~mL})$ de persulfato de amônio $(0,256 \mathrm{~g})$ lentamente foi adicionada, gota a gota, à suspensão anterior e mantida sob agitação durante $35 \mathrm{~min}$. Ao final, a suspensão de PPy-NPs com uma concentração de $2 \mathrm{mg} / \mathrm{mL}$ de soluto foi mantida a $4^{\circ} \mathrm{C}$, durante $24 \mathrm{~h}$. As medidas de tamanho de partículas foram realizadas no ZetaSizer Nano ZS90 (Malvern).

A concentração inibitória mínima (CIM) e a concentração bactericida mínima (CBM) de PPyNPs em água foram determinadas por meio da metodologia de microdiluição em caldo, seguindo as recomendações do Clinical Laboratory Standards Institute (Methods..., 2015). Foram usados como controles as cepas $S$. aureus ATCC 25938 e S. epidermidis ATCC 12228. As PPyNPs em água, com uma concentração inicial de $2 \mathrm{mg} / \mathrm{mL}$, foram diluídas 1:2, com MGB já inoculado com o isolado a ser testado. As concentrações de PPy-NPs testadas foram $500 \mu \mathrm{g}$, $250 \mu \mathrm{g}, 125 \mu \mathrm{g}, 62,5 \mu \mathrm{g}, 31,25 \mu \mathrm{g}$ e $15,63 \mu \mathrm{g}$. As microdiluições em placas foram incubadas a $35^{\circ} \mathrm{C}$, por $20 \mathrm{~h}$, sendo realizadas leituras de DO a $600 \mathrm{~nm}$ no leitor de microplacas de ELISA (Multiskan Go Thermo Scientific), em dois momentos (0h e 20h). A CIM foi definida como a menor concentração de PPy-NPs em água que inibiu mais do que $75 \%$ do crescimento bacteriano, e a CBM como a mínima concentração que resultou na inativação de $99 \%$ das células bacterianas, determinada pelo método de repique em placa de ágar Mueller Hinton, não se observando crescimento bacteriano visível.

Um total de 138 isolados de S. aureus foi identificado mediante a classificação fenotípica e a amplificação do fragmento de 296bp do gene nuc. Do total de isolados recuperados, 112 $(81,16 \%)$ foram de amostras de leite de vacas, e $26(18,84 \%)$ de leite de cabras. Cinquenta e quatro isolados $(48,21 \%)$ obtidos de leite de vaca não produziram biofilme, $36(32,14 \%)$ apresentaram fraca produção de biofilme, $17(15,18 \%)$ moderada produção, e cinco $(4,46 \%)$ forte produção de biofilme. Por outro lado, a produção de biofilme nos $S$. aureus obtidos de cabras foi negativa em $18(69,23 \%)$ isolados e fraca em oito isolados $(30,77 \%)$.

Tendo em vista que a formação de biofilme é um dos mais importantes mecanismos de sobrevivência da bactéria que vive no nicho extracelular (Melchior et al., 2006), a alta frequência de isolados não produtores de biofilme observada no presente estudo sugere que a pressão de seleção microbiana exercida por antimicrobianos é inferior nos isolados incluídos neste estudo, quando comparados com os isolados de $S$. aureus causadores de mastites dos países incluídos na coleção internacional (Bélgica, Canadá, Itália e Suíça) (Bardiau et al., 2016). Outro estudo realizado no Brasil obteve resultados similares aos descritos no presente trabalho em relação ao número de isolados não produtores de biofilme. Lee et al. (2014) identificaram o maior número de isolados de $S$. aureus agrupados na categoria de não produtores de biofilme.

O resultado do tamanho de partículas indica uma distribuição para valores na ordem de $16,79 \pm 4,95 \mathrm{~nm}$, com índice de polidispersão de 0,5832 e potencial zeta de $-60,3 \mathrm{mV}$. Esse valor é 
justificado pela camada de surfactante aniônico (SDS) que recobre o polipirrol, fornecendo a estabilidade para a dispersão em meio aquoso. A CIM das PPy-NPs foi de $125 \mu \mathrm{g} / \mathrm{mL}$ para $100 \%$ dos isolados avaliados (138). O efeito inibitório no crescimento bacteriano foi resultado da atividade bactericida das PPy-NPs nessa concentração $(125 \mu \mathrm{g} / \mathrm{mL})$, sendo isso constatado nos testes para determinar a CBM (Fig. 1).

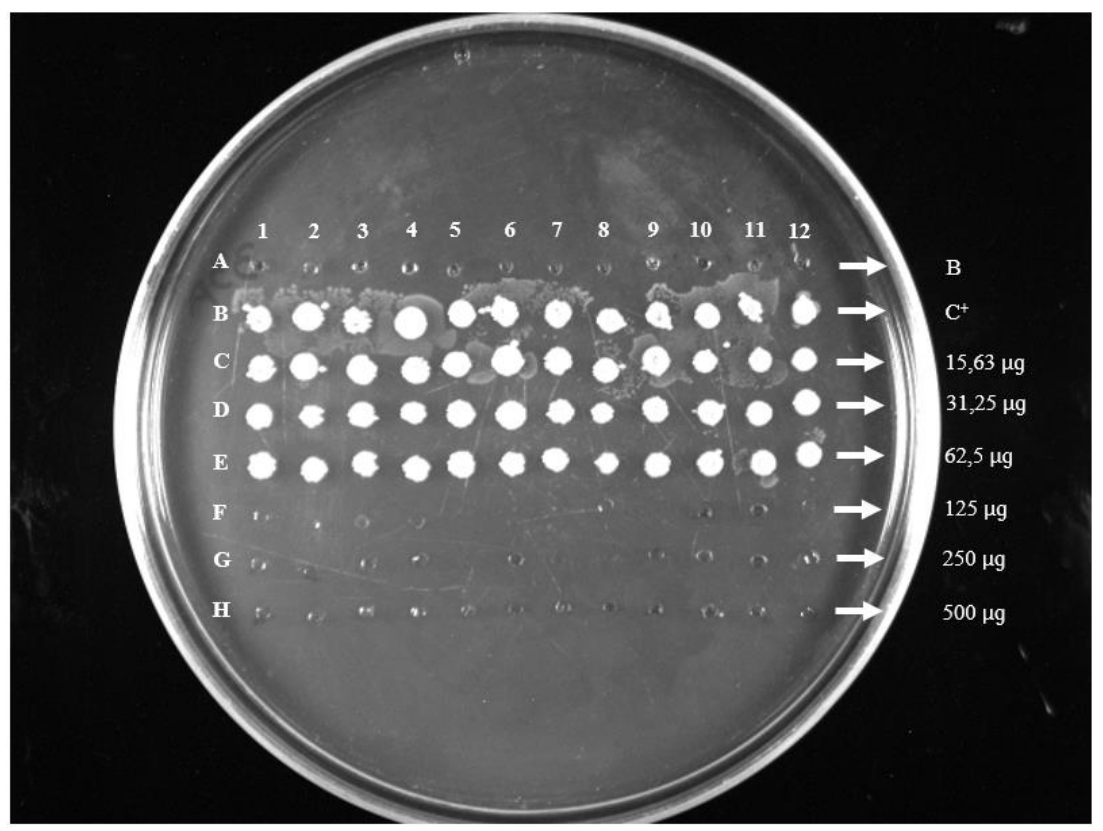

Figura 1. Concentração mínima bactericida de PPy-NPs. B: caldo Mueller Hinton, $\mathrm{C}^{+}$: controle positivo de

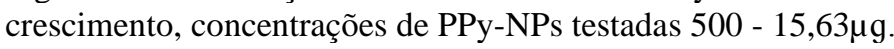

A contribuição do presente estudo está na determinação da menor concentração na qual essas PPy-NPs têm atividade bactericida diante de isolados de $S$. aureus obtidos de vacas e cabras com mastite, com diferentes perfis de virulência quanto à produção de biofilme. Esse achado vislumbra um novo caminho na prevenção e terapêutica das mastites causadas por $S$. aureus, uma vez que esse microrganismo é capaz de expressar uma ampla gama de fatores de virulência que permitem a evasão do sistema imune do hospedeiro e a diminuição na eficácia dos tratamentos com diferentes antimicrobianos.

Com relação à biocompatibilidade do PPy, já foram realizados estudos em sistemas in vitro e in vivo, e os resultados obtidos sugerem que compostos à base de PPy não oferecem risco para os tecidos vivos (Wang et al., 2004). As interações eletrostáticas estabelecidas entre as PPy-NPs e a bactéria desencadeiam a desestabilização da parede celular, com posterior lise bacteriana (Varesano et al., 2013), e, até o presente momento, não foram descritos mecanismos de resistência pela bactéria, o que constitui um importante fator para incentivar futuras pesquisas com essas PPy-NPs.

As PPy-NPs em água apresentaram efeito bactericida a partir da concentração de $125 \mu \mathrm{g} / \mathrm{mL}$ em $100 \%$ dos isolados de Staphylococcus aureus avaliados, independentemente da capacidade de produção de biofilme. Esses resultados dão suporte para estudos futuros da atividade de PPyNPs in vitro e in vivo.

Os autores gostariam de mostrar agradecimentos à Fundação de Amparo à Ciência e Tecnologia de Pernambuco (FACEPE), com o número de processo IBP-0439-5.05/12, e ao Conselho Nacional de Desenvolvimento Científico e Tecnológico $(\mathrm{CNPq})$, com o número de processo 442746/2014-8.

Palavras-chave: biofilme, composto de polímero, infecção intramamária, $\mathrm{S}$. aureus 


\begin{abstract}
The aim of the present study was to evaluate the antibacterial behavior of polypyrrole nanoparticles (PPy$N P S)$ in water against biofilm producer or not $\mathrm{S}$. aureus isolated from cows and goats with mastitis. One hundred and thirty-eight isolates of $\mathrm{S}$. aureus were initially evaluated for biofilm formation by spectrophotometry in microplates. In addition, the minimum inhibition concentration (MIC) and minimum bactericidal concentration (MBC) of PPy-NPs in water for planktonic S. aureus were determined. From the bovine samples analyzed, $5(4.46 \%) \mathrm{S}$. aureus isolates showed a strong biofilm production, 17 (15.18\%) moderate production, $36(32.14 \%)$ with weak production and 54 (48.21\%) did not produce biofilms. Strains from goats (26) showed no biofilm production in 18 (69.23\%) strains and weak biofilm production in 8 $(30.76 \%)$ strains. The MIC and MBC of S. aureus to PPy-NPs were found in the same concentration $(125 \mu \mathrm{g} / \mathrm{mL})$ in all strains tested, regardless of biofilm production or not. This finding provides a new insight into the interaction between PPy-NPs and S. aureus, and will offer potential benefits for the control of mastitis.
\end{abstract}

Keywords: biofilm, polymer composite, intramammary infection, S. aureus

\section{REFERÊNCIAS}

ACOSTA, A.C.; OLIVEIRA, P.R.F.; ALBUQUERQUE, L. et al. Frequency of Staphylococcus aureus virulence genes in milk of cows and goats with mastitis. Pesqui. Vet. Bras., v.38, p.2029-2036, 2018.

BARDIAU, M.; CAPLIN, J.; DETILLEUX, J. et al. Existence of two groups of Staphylococcus aureus strains isolated from bovine mastitis based on biofilm formation, intracellular survival, capsular profile and agr-typing. Vet. Microbiol., v.185, p.1-6, 2016.

HALASA, T.; HUIJPS, K.; ØSTERÅS, O. et al. Economic effects of bovine mastitis and mastitis management: a review. Vet. Q., v.29, p.18-31, 2007.

LABORATORY and field handbook on bovine mastitis. Madison, WI.: National Mastitis Council Inc., 1999.

LEE, S.H.I.; MANGOLIN, B.L.C.; GONÇALVES, J.L. et al. Biofilm-producing ability of Staphylococcus aureus isolates from Brazilian dairy farms. J. Dairy Sci., v.97, p.18121816, 2014.

MELCHIOR, M.B.; VAARKAMP, H.; FINKGREMMELS, J. Biofilms: a role in recurrent mastitis infections? Vet. J., v.171, p.398-407, 2006.
MERINO, N.; TOLEDO-ARANA, A.; VERGARA-IRIGARAY, M. et al. Protein Amediated multicellular behavior in Staphylococcus aureus. J. Bacteriol., v.191, p.832-843, 2009.

METHODS for dilution antimicrobial susceptibility tests for bacteria that grow aerobically. Document M07-A10. Approved standard. 10.ed. Wayne, PA: CLSI, 2015. 35p.

STEPANOVIĆ, S.; VUKOVIĆ, D.; DAKIĆ, I. et al. A modified microtiter-plate test for quantification of staphylococcal biofilm formation. J. Microbiol. Methods, v.40, p.175179, 2000.

VARESANO, A.; VINEIS, C.; ALUIGI, A. et al. Antibacterial efficacy of polypyrrole in textile applications. Fibers Polym., v.14, p.36-42, 2013.

WANG, X.; GU, X.; YUAN, C. et al. Evaluation of biocompatibility of polypyrrole in vitro and in vivo. J. Biomed. Mater. Res. Part. A, v.68, p.411422, 2004.

ZECCONI, A.; CESARIS, L.; LIANDRIS, E. et al. Role of several Staphylococcus aureus virulence factors on the inflammatory response in bovine mammary gland. Microbial Pathogenesis, v.40, p.177-183, 2006. 